\title{
OPINION
}

\section{Ethics Lessons Learned While Editing the Monthly: Modern Publishing Is Raising New Issues}

\author{
Scott T. Chapman
}

ABSTRACT. A former Monthly editor discusses self-plagiarism, forged documents, and the ethics of double-blind reviewing.

As a pragmatist who instinctively trusts people, my fiveyear term as editor of the American Mathematical Monthly ended much differently than it began. After four years of editing with little or no ethical issues, two significant ones emerged during year five. The first involved an author who republished in the Monthly a work previously published elsewhere; it became the first retraction in the 121-year history of the Monthly. The second involved an author who forged acceptance letters for papers that he never had submitted. While these are extreme cases, they made me think deeply about ethical issues in mathematical publication and how they have changed so drastically since I began publishing papers thirty years ago.

I doubt that many of the professional mathematicians who are reading this have ever taken a course in academic ethics or even listened to a seminar on the subject. Most of us (and I include myself) learned mathematical ethics

Scott T. Chapman is distinguished professor at Sam Houston State University. His email address is scott. chapman@shsu. edu.

For permission to reprint this article, please contact:

reprint-permission@ams.org.

DOI: http://dx.doi.org/10.1090/noti1740 secondhand as we worked our way through graduate school or our first tenure-track jobs. We basically know what not to do, but with the ever-changing landscape of academic publishing, the lines that seemed so clear thirty years ago are sometimes much less fine. For instance, does posting a paper to the arXiv constitute a publication? Or, if I use a photograph or table taken from the internet public domain, do I need to credit where it came from? The internet has opened an entire new can of ethical worms that we are just now beginning to sort out.

So what are the rules? I found when I started dealing with the self-plagiarism case that there is no Bible for mathematical ethics. There are many different sources that one can use. I was quite surprised to learn that the Mathematical Association of America has no written ethics guidelines with regards to publishing. The three best sources that I could find were ethical guidelines adopted by the American Mathematical Society [2], the European Mathematical Society [4], and the London Mathematical Society [5]. The Procedures Manual of the AMS Committee on Professional Ethics (COPE) [1] has an appendix with many hypothetical ethics violations and the following disclaimer: "These are guidelines, not a collection of rigid rules." Even in the most clear-cut of cases, one must be ready to deal with gray area.

Obviously, forging acceptance letters is not a gray area. The rules involving plagiarism of another author's work are pretty clear-cut, but those involving self-plagiarism are not. Retractions are liable to become more commonplace 
as the number of online journals continues to increase. If you've written something previously, when and how can you use it again? Here is an excerpt from the Australian Code for the Responsible Conduct of Research [3, Section 4.7]:

It is not acceptable to include the same research findings in several publications, except in particular and clearly explained circumstances, such as review articles, anthologies, collections, or translations into another language. An author who submits substantially similar work to more than one publisher, or who submits work similar to work already published, must disclose this at the time of submission.

Moreover, authors need to keep in mind that copyright laws apply. Yes, you wrote it, but if a publisher holds a copyright on an article, then technically you have given up ownership. For academic publication, the doctrine of "fair use" comes into play, and reproduction of short passages can normally be satisfied by the appropriate referencing methods. Using more than snippets from a copyrighted article requires written permission from the copyright holder, and this in theory could involve monetary considerations. When the Monthly wanted to republish a Pi Day crossword puzzle from the New York Times, I was dismayed to learn that this would cost thousands of dollars.

To be on the safe side, if you plan on using significant portions of your prior work in a new article, be completely up-front about this. Include in an introductory paragraph a statement to that effect ("This paper includes portions of previous work $[\mathrm{XX}]$..."). Carefully reference theorems and other results. If you are taking more than a few lines verbatim, obtain a copyright release and footnote this on the first page. Most academic publishers will do this with no charge. It is best here to err on the side of cautionself-plagiarism can be dealt with as severely as the more traditional plagiarism of another's works.

The remainder of this note will tread on even grayer area. In August of 2012, the MAA instituted a policy of double-blind reviewing for all papers submitted to the Monthly and its other two journals (Mathematics Magazine and the College Math Journal). Double-blind reviewing was already in use at the College Math Journal, but its implementation at the Monthly broke new ground. The theory behind double-blind reviewing is that most of the bias in publishing can be eliminated if the authors and referees are unknown to each other.

Question 1. Whose responsibility is it that the manuscript does not contain information that identifies the author(s)?

Question 2. If authors submit a double-blind manuscript, can they still make copies of it available (either online or otherwise) that identify the authors? More specifically, can the authors post a copy on the arXiv?

Question 3. If a potential reviewer of a double-blind manuscript determines the identity of the author(s), can he or she still act as referee?
As I began navigating the world of double-blind, I developed strong opinions on all three of these questions. As an editor who handled nearly 900 manuscripts a year, my answers are a mix of practical methods and the philosophy behind double-blind.

As to Question 1, the initial answer seems simple: it is up to the author to remain anonymous. Yet I saw many instances where a highly regarded author would have benefited if the referees knew who he or she was. How much can the editor be expected to do? The job of editing is hard enough without adding the additional burden of screening every manuscript line by line for subtle clues on who the author is. Moreover, in today's Google-like atmosphere, if referees want to know who wrote an article, then they can likely find out. The system cannot be completely foolproof. The best we can do is to give the author the responsibility to keep the submission anonymous. I state this as the first in a short series of double-blind editorial axioms.

Double-Blind Axiom 1. The onus of anonymity in the double-blind process lies mainly on the author.

Question 2 involves perhaps the most frequently asked question I got while editing the Monthly. Can I post a paper I have submitted to my webpage or to the arXiv? The practice of posting preprints is widespread and universally accepted. When we used traditional reviewing, the answer was clearly "yes." Logic might seem to indicate that in the double-blind situation that answer is "no." Unlike the previous situation, in this case I think the onus is on the journal and the editor, rather than the author.

I think it would be completely within a double-blind journal's right to prohibit authors from openly posting submitted work. During my double-blind years at the Monthly, I was hesitant to do this. I was concerned that a complete prohibition on using the arXiv might have a significant impact on our submission rate. Thus, a double-blind journal needs a clear policy on this, as I state in Double-Blind Axiom 2.

Double-Blind Axiom 2. A journal that uses double-blind reviewing should have a clear and easily found policy concerning the posting of work that is under consideration.

I think Question 3 boils down to an issue that we are all used to dealing with in the traditional refereeing system: Can I objectively referee this work? There seems to be no concrete definition of "conflict of interest." If you cannot read the paper and make a decision that is universal regardless of the identity of the author, then you should not referee the paper. A good editor should police this and not send papers out to co-authors or others who have clearly worked closely with the author. If you believe you know who the author is and think this could play a role in your decision, then bring it to the editor's attention. It is then his or her job to the make the call.

Double-Blind Axiom 3. Issues involving conflict of interest for potential referees should be brought to the attention of the editor, who is the final arbiter in such matters.

Shortly after my term as editor of the Monthly ended in 2016, the MAA convened a task force (chaired by former Monthly Editor Dan Velleman) to review the situation at its journals with respect to double-blind refereeing. Its report 
discusses, among other issues, the three questions above and offers recommendations on how the MAA should proceed with developing editorial policy.

\section{References}

[1] American Mathematical Society Committee on Professional Ethics (COPE) Procedures Manual, www. ams.org/about-us /governance/policy-statements/copemanual.pdf.

[2] American Mathematical Society Policy Statement on Ethical Guidelines, www. ams.org/about-us/governance/policy -statements/sec-ethics.

[3] Australian Code for the Responsible Conduct of Research, https://www.adelaide.edu.au/research-services /oreci/integrity/docs/australian-code-responsible -conduct-research.pdf.

[4] Code of Practice - the European Mathematical Society, euro-math -soc.eu/system/files/uploads/COP-approved.pdf.

[5] Ethical Policy for the Journals of the London Mathematical Society,https://www. $7 \mathrm{~ms}$.ac.uk/sites/1ms.ac.uk/files /Publications/EthicalPolicy.pdf.

EDITOR'S NOTE. For a review of how the AMS handled ethics see the April 2010 Notices article on "Awareness of Ethical Pitfalls: A Requirement for Professional Protection" by Catherine Roberts, https: //www. ams .org /notices/201004/rtx100400485p.pdf.

\section{Photo Credit}

Author photo by Robin Jackson, Dallas, Texas.

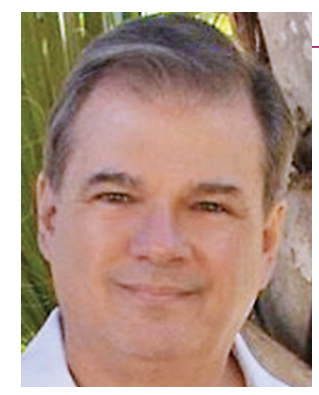

Scott T. Chapman

\section{ABOUT THE AUTHOR}

Scott T. Chapman is scholar in residence and distinguished professor of mathematics at Sam Houston State University in Huntsville, Texas. In December of 2016 he finished a five-year appointment as editor of the American Mathematical Monthly. His editorial work, numerous publications in the area of nonunique factorizations, and years of directing REU programs led to his designation in 2017 as a Fellow of the American Mathematical Society.

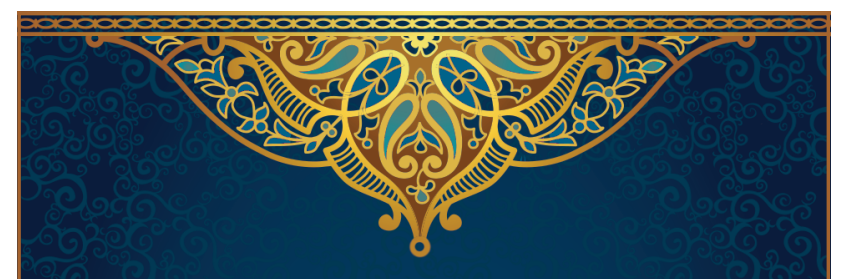

\section{FEATURED TITLE FROM 매 HINDUSTAN $\square \square$ BOOK AGENCY}

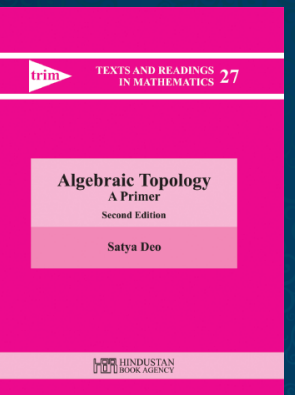

Algebraic Topology

A Primer

(Second Edition)

Satya Deo, Harish-Chandra

Research Institute, Allahabad, India

This is the second (revised and enlarged) edition of the book originally published in 2003 . It introduces the first concepts of algebraic topology such as general simplicial complexes, simplicial homology theory, fundamental groups, covering spaces, and singular homology theory in detail. The text has been designed for undergraduate and beginning graduate students of mathematics. It assumes a minimal background of linear algebra, group theory, and topological spaces.

The author deals with the basic concepts and ideas in a very lucid manner, giving suitable motivations and illustrations. As an application of the tools developed in this book, some classical theorems such as Brouwer's fixed point theorem, the Lefschetz fixed point theorem, the Borsuk-Ulam theorem, Brouwer's separation theorem, and the theorem on invariance of domain are proved and illustrated. Most of the exercises are elementary, but some are more challenging and will help readers with their understanding of the subject.

Hindustan Book Agency; 2018; 358 pages; Softcover; ISBN: 978-93-86279-67-5; List US\$52; AMS members US\$41.60; Order code HIN/74

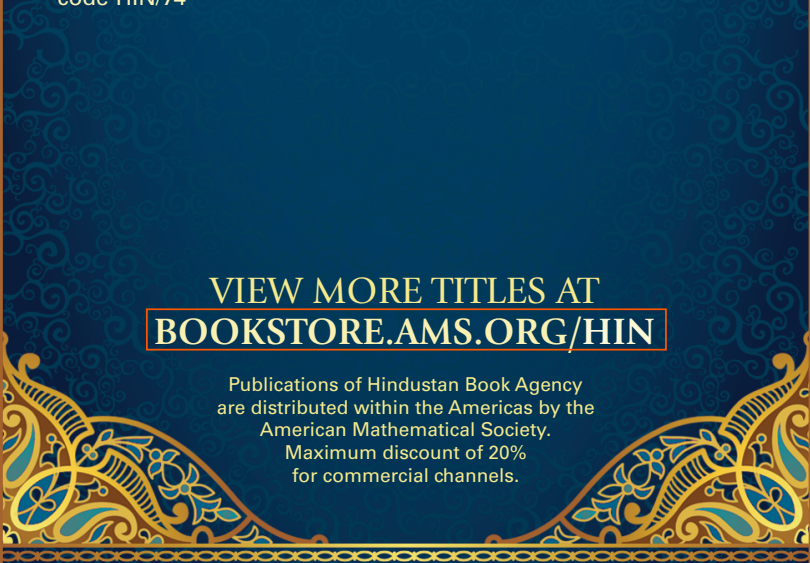

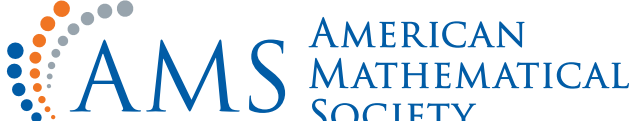

$$
\begin{aligned}
& \text { SOCIETY }
\end{aligned}
$$

